\title{
Ventral Phalloplasty
}

Tariq S. Hakky, Alejandro R. Rodriguez, Justin Parker, Jorge L. Lockhart, John Honeymeyer III, Rafael E. Carrion

Department of Urology, Moffitt Cancer Center, Tampa, FL, USA

\section{ABSTRACT}

Purpose: To present the surgical technique of ventral phalloplasty as an adjunct procedure to the classic prosthetic surgery. Materials and Methods: In this video we demonstrate how to perform a ventral phalloplasty in a patient that has undergone a penile prosthesis implantation. Our technique consists of: delineation of the penile scrotal web, excision of this redundant skin, and re-approximation of the wound to mimic the natural median raphe.

Results: The ventral phalloplasty improves the perception of phallic length, as well as patients' satisfaction after prosthetic surgery.

Conclusion: Penile length perception is the main concern of patients that have undergone penile prosthesis implantation. In this video we demonstrate that the ventral phalloplasty can improve perception of phallic length, and can be an important adjunct to the classic prosthetic surgery.

\section{ARTICLE INFO}

Available at: www.brazjurol.com.br/videos/july_august_2012/hakky_565_566video.htm

Int Braz J Urol. 2012; 38 (Video \#5): 565_566

Submitted for publication:

May 30, 2011

Accepted after revision:

January 12, 2012
Correspondence address:

Dr. Tariq S. Hakky

Department of Urology,

Moffitt Cancer Center, Tampa, FL, USA

Tampa, Florida, USA

E-mail: tariq7@gmail.com 


\section{EDITORIAL COMMENT}

The video nicely demonstrates a simple technique which improves the cosmetic appearance of the phallus following implantation of a penile prosthesis.

Decrease in penile length and volume have been reported following radical prostatectomy (1). Studies have not shown a significant decrease in penile length after implantation of a penile prosthesis. Despite this fact, patients that undergo implantation of a penile prosthesis often complain of a perceived a loss of phallic length (2). To deal with this problem, urologists can either try to increase the true length of the penis or improve the protruberance of the phallus without true length increase. Several options are available.

Suprapubic lipectomy which was first reported by Horton and colleagues in 1987 can help release a penis that is partially hidden by suprapubic fat (3). Additional penile length can be achieved by division of the penile suspensory ligament. This must be combined with post-operative penile stretching in order to achieve lasting success (4). Augmentation corporoplasty which involves corporal incisions and grafting can be used to improve both penile length and girth (5). Alternatively, after a period of time, one can place larger implant cylinders in the corpora (6). Scrotoplasty has been commonly used in children to help improve the cosmetic appearance of the hidden penis due to penile webbing (7). Ventral phalloplasty modifies this technique by excising skin in a convex fashion to preserve the scrotal contour.

Perceived loss of penile length is a common problem after penile prosthesis implantation. This easily performed technique changes the position of the penoscrotal angle and gives patients the perception of preserved penile length.

\section{REFERENCES}

1. Fraiman MC, Lepor H, McCullough AR: Changes in Penile Morphometrics in Men with Erectile Dysfunction after NerveSparing Radical Retropubic Prostatectomy. Mol Urol. 1999; 3: 109-115.

2. Deveci S, Martin D, Parker M, Mulhall JP: Penile length alterations following penile prosthesis surgery. Eur Urol. 2007; 51: 1128-31.

3. Horton CE, Vorstman B, Teasley D, Winslow B: Hidden penis release: adjunctive suprapubic lipectomy. Ann Plast Surg. 1987; 19: 131-4.
4. Borges F, Hakim L, Kline C: Surgical technique to maintain penile length after insertion of an inflatable penile prosthesis via infrapubic approach. J Sex Med. 2006; 3: 550-3.

5. Colombo F, Casarico A: Penile enlargement. Curr Opin Urol. 2008; 18: 583-8.

6. Wilson SK, Delk JR 2nd, Mulcahy JJ, Cleves M, Salem EA: Upsizing of inflatable penile implant cylinders in patients with corporal fibrosis. J Sex Med. 2006; 3: 736-42.

7. Perlmutter AD, Chamberlain JW: Webbed penis without chordee. J Urol. 1972; 107: 320-1.

Dr. Hubert Swana

Pediatric Urology

Nemours Children's Clinic Orlando, USA

E-mail: hswana@nemours.org 